
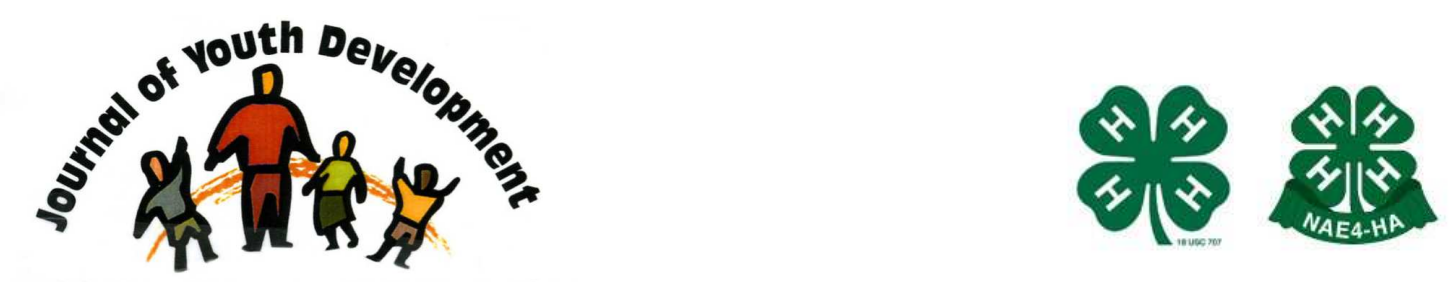

Bridging Research \& Practice

\title{
The Arthur Interactive Media Study: Initial Findings From a Cross-Age Peer Mentoring and Digital Media-Based Character Development Program
}

\author{
Edmond P. Bowers \\ Clemson University \\ edmondb@clemson.edu \\ Lacey J. Hilliard \\ Tufts University \\ Milena Batanova \\ Tufts University \\ Danielle C. Stacey \\ Tufts University \\ Jonathan M. Tirrell \\ Tufts University \\ Katherine Wartella \\ Tufts University \\ Richard M. Lerner \\ Tufts University
}

Acknowledgement: This research was supported in part by a grant from the John Templeton Foundation. We also acknowledge the research support of two former team members, Kathleen $\mathrm{N}$. Greenman and Caitlin Doering, and another member, Heidi L. Johnson, who is still actively involved with the AIM study. 


\title{
JOURNAL OF YOUTH DEVELOPMENT \\ bridging research and practice

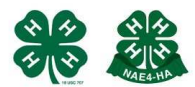

Volume 10, Number 3, Special Issue 2015

Article 151003FA004

\section{The Arthur Interactive Media Study: Initial Findings From a Cross-Age Peer Mentoring and Digital Media-Based Character Development Program}

\author{
Edmond P. Bowers \\ Clemson University
}

Lacy J. Hilliard, Milena Batanova, Danielle C. Stacey, Jonathan M. Tirrell

Katherine Wartella, and Richard M. Lerner

Tufts University

\begin{abstract}
In the midst of increasing emphasis on the inclusion of character education in both school and out-of-school time programs, digital technologies have become ubiquitous in these settings. Based on the potential of these technologies to enhance children's character development, the Arthur Interactive Media (AIM) study investigated if one specific unit or set of digital media-based activities engaged youth in discussions about character. First and second grade students were paired with fourth and fifth grade students, respectively, while engaging with an online interactive graphic novel (IGN) about a character-relevant story based on the Arthur cartoon series. Teachers $(n=8)$ completed surveys about the AIM Unit, and conversations between cross-age peer dyads ( $n=$ 27 dyads) during their engagement with the IGN were analyzed. Results indicated that teachers were very satisfied with the materials and reported that children were very engaged throughout. Analyses of children's conversations indicated that children participated in character-relevant conversations involving humility, forgiveness, and future-mindedness while engaging with the IGN.
\end{abstract}

\section{Introduction}

The past 20 years have seen a renaissance of studies about character virtues and strengths (e.g., Damon, 2008; Peterson \& Seligman, 2004) and educational models designed to promote character among youth both in school and out-of-school time (OST) settings (e.g., Damon, 1988; Lapsley \& Narvaez, 2006). In addition, character development has been seen as an imperative need among educators, practitioners, and researchers alike, ranking even above concerns such as academic achievement (Myers, 2000), as states have adopted laws and policies that compel schools to address character-relevant issues (Farrington \& Ttofi, 2009). 
Over the same period, as pressure for character education efforts mounted, the 1990s also marked a turning point in the evolution of digital technology and media. The onset of more powerful and less expensive electronic devices began to shape not only the personal lives of young people but also their education both inside and beyond the classroom (Bers \& Kazakoff, 2013). The usefulness of technology to enhance learning has been recognized for several decades (Clark, 1998; Jonassen, Howland, Moore, \& Marra, 2003); however, much of this work has focused on the role of technology in promoting cognitive or academic success. Much less research has examined the application of technology to promote character in young people (see Bailey, Tettegah, \& Bradley, 2006; Narvaez, Mattan, MacMichael \& Squillace, 2008 for some examples).

To leverage the increased demands and the potential for the integration of technology and character education in schools and out-of-school time (OST) programs, the Arthur Interactive Media (AIM) study is a joint collaboration between developmental scientists and children's media experts to design, implement, and evaluate a cross-ager peer mentoring and digital media-based character education program that can be used in both school and OST settings. The program pairs students of different ages (cross-age peer dyads) to promote rich conversations and reflections about character-relevant issues (e.g., bullying, friendship) that reflect salient character virtues (e.g., humility, honesty). Little Buddies (first and second graders) are paired with Big Buddies (fourth and fifth graders) as part of the program. To enhance opportunities for conversation and reflection, the program uses digital interactive features adapted from episodes and characters of the Arthur (the aardvark) cartoon series. In the present study, we focused on one unit of the initial testing of the AIM program, to examine 1. teachers' reported satisfaction with the materials; 2 . teachers' reported student engagement with the materials; and 3. students' conversations during their joint engagement with the digital media materials in particular.

\section{Description of the Current AIM Unit}

Whereas the program in its entirety involves digital interactive features comprised of comics and games, the interactive feature that marked the program unit investigated in this study was an interactive graphic novel (IGN). A blend of storytelling and interactive activities, IGNs contain animated vignettes that allow children to experience individuals' different perspectives and feelings, and to choose from various situations how characters and scenes can play out. Storylines focus on character virtues or strengths important for interacting and relating to others in positive ways, such as showing humility and forgiveness. Animated vignettes, such as those provided in the current IGN, have been identified as a way to provide a more dynamic and authentic representation of a situation (Tettegah, 2005) than traditional narrative vignettes that have marked much of the history of moral and character development (Kohlberg, 1969; Nucci, 1997).

For the present study, we implemented and evaluated an IGN and related materials based on the Arthur episode, "So Funny I Forgot to Laugh." In this episode, Arthur thinks that his jokes about a friend's new sweater are all in good fun, but the friend's feelings get hurt and other friends or bystanders of the situation get angry with Arthur as the story progresses. Arthur is given several opportunities to acknowledge that his teasing turned into bullying and to apologize or seek forgiveness from his friend. As part of the IGN experience, children progress through the story and stop at several key points where they are asked questions about Arthur's and his friends' thoughts, feelings, and behaviors, and then they are presented with interactive screens that allow them to hear what Arthur and friends are thinking and feeling. At the end, 
children are also given three different story endings to decide on and discuss in terms of which one is better than the other. Figure 1 presents several screenshots from the IGN.

Figure 1

Screenshots of the introductory page and several scenes from the online Arthur interactive graphic novel (IGN).
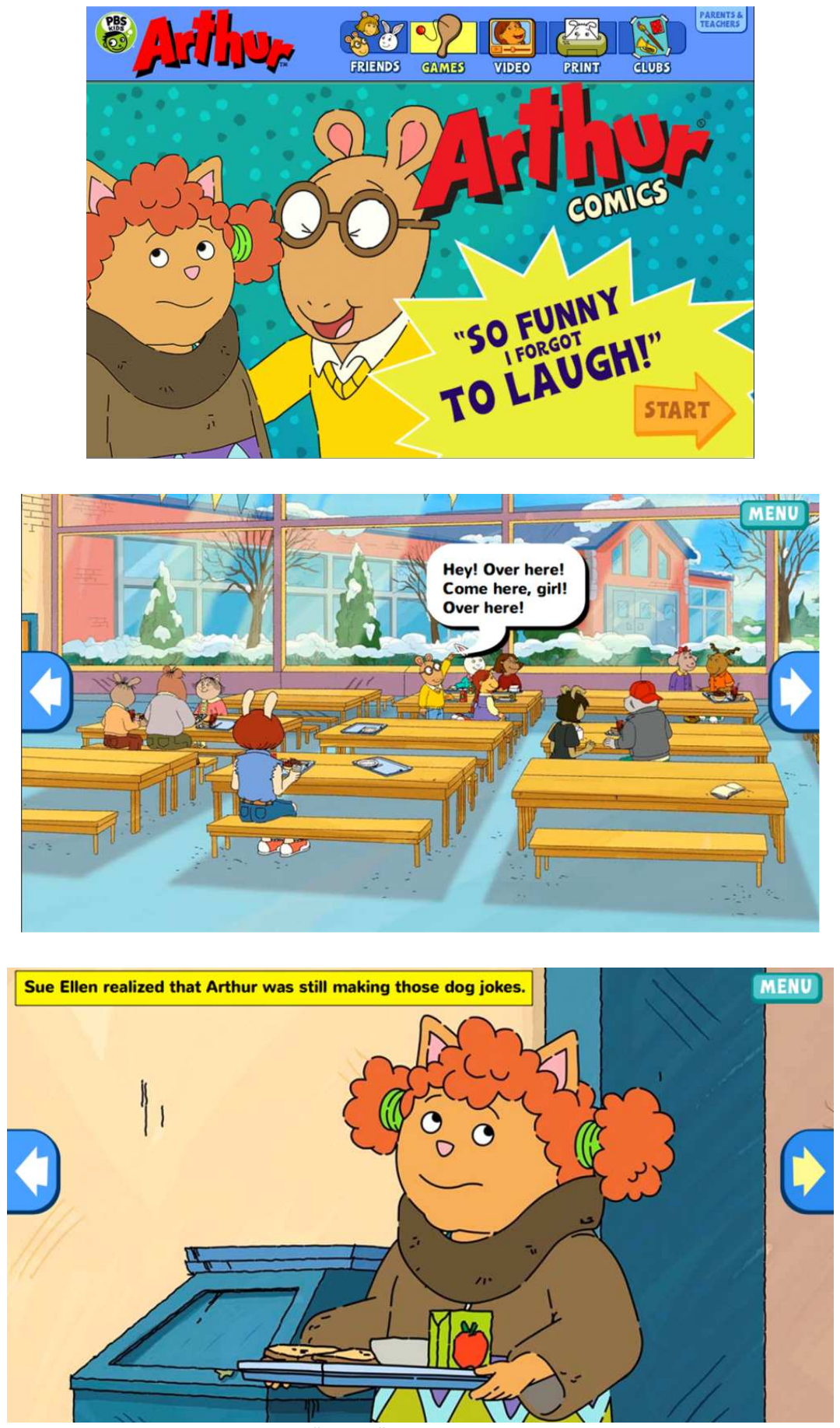

(c) 2015 WGBH Educational Foundation. All rights reserved. "Arthur" \& the other Marc Brown ARTHUR characters and underlying materials (including artwork) TM and (C) Marc Brown. The Arthur Interactive Media Buddy Project was made possible through the support of a grant from the John Templeton Foundation. The opinions expressed in this publication are those of the author(s) and do not necessarily reflect the views of the John Templeton Foundation. 
Although the present study examined one specific unit of the initial AIM program within schoolbased settings, the program was developed to be "portable" in that it can be implemented in a diversity of settings in which youth have access to digital media. The underlying framework for the AIM program is consistent with the philosophies that guide youth development programs (Lerner et al., 2011). For example, the AIM program reflects the "Big 3" (Lerner, 2004) of youth development programs as the program is intended to develop sustained relationships between cross-age peer dyads; build important life skills in youth; and provide youth with opportunities to take on leadership roles in their schools and communities. In addition, the AIM program adheres to the practices of effective character education programs that enhance its utility in both school and OST settings. That is, the AIM program uses a sequenced step-by-step training approach (S) and active forms of learning (A); it focuses sufficient time on skill development (F); and it has explicit learning goals (E) (Durlak, Weissberg, \& Pachan, 2010). As schools face a myriad of constraints to implementing character education programs during the school day (Sojourner, 2012), many of these programs are forced to move to OST settings and the AIM program carries great potential for being applied to such settings.

\section{Theoretical and Empirical Support for the AIM Study}

The AIM study is grounded in a relational developmental systems (RDS) model of character development (Lerner \& Callina, 2014). In this model, character is a multifaceted relational construct that develops through mutually beneficial relations between the person and the context. Within the current AIM unit involving the IGN, "the right thing to do" for Arthur and his friends depends on the storyline and situational features. In the same way, how children engage with the IGN and decide what "the right thing to do" is, arise from the conversations that they have with their cross-age peers. These conversations occur as a result of the dyads' joint engagement with the IGN, and they involve multiple dimensions of character that are relevant to successful and positive peer interactions.

Cross-age peer dyads. The essential influence of social interactions for character development can be traced to foundational work in the field of moral development. Peers serve as a key contextual resource for promoting moral and character development in children (Larson, Jensen, Kang, Griffith, \& Rompala, 2012). There is extensive empirical evidence that peers can serve as models for child behavior in various contexts, and peer relations provide one of the primary socialization domains for children (Barber \& Olsen, 1997). The mutual, interactive quality of peer relationships facilitates behavioral development, particularly positive character and moral development (Walker, Hennig, \& Krettenauer, 2000).

Whereas peer may connote "of the same age," the term cross-age is a necessary qualifier. For example, cross-age peer mentors are peers who are two or more grades or years older than their mentee, brought together for both educational and social development (Burrell, Woods, Pikes, \& Holliday, 2001). Indeed, a two-year age gap between peers has been linked with more positive outcomes (Karcher, 2007). In addition, cross-age peer mentors provide a potential mechanism for the scaffolding of positive characteristics related to children's character development (Turner \& Berkowitz, 2005) as cross-age peer mentoring programs are often aimed at promoting leadership, interpersonal skills, and understanding difficult concepts (Tasca, 2002).

Digital media. Children's use of digital media was also a salient contextual feature of this study as the digital interactive features were seen as a powerful resource to promote opportunities for rich character-relevant conversations. Researchers have provided strategies for using technology to promote positive outcomes in children (Clark, 1998). Many of these 
suggestions are reflected in the design of the AIM program. For example, Calvert (2015) has identified several characteristics of effective educational technologies and media including interactive format, likeable protagonists, theme-based content, and support from complementary materials. In addition, findings suggest prosocial content may influence social development by building emotional competencies and reducing aggression oriented attitudes (Narvaez et al., 2008; Sestir \& Bartholow, 2010).

Scholars and practitioners are also increasingly interested in encouraging and supporting children's learning through joint media engagement, that is, "spontaneous and designed experiences of people using media together" (Takeuchi \& Stevens, 2011, p. 9). The term was coined to extend the concept of co-viewing media beyond television to actively participating and learning through media (Takeuchi \& Stevens, 2011); however, much of the literature has been on parent-child joint media engagement and the few studies on friends using media collaboratively have largely involved video game play (e.g., Stevens, Satwicz, \& McCarthy, 2008). With technology becoming a salient context for youth within and beyond the classroom walls, character education initiatives may benefit by exploring how the use of technology-based tools and joint media engagement in particular can help foster positive character among young people.

\section{The present study}

The purpose of this study was to describe the first set of pilot materials from one AIM unit, and to examine both the usability of these materials and the engagement between cross-age peer dyads during their character-relevant discussions of the IGN material in particular. Therefore, we assessed teachers' satisfaction with the materials and their reports of children's engagement with the materials. We also examined whether the IGN experience promoted conversations between cross-age peer dyads (i.e., Big and Little Buddies), and more importantly, if it did, whether the conversations between the Big and Little Buddies related to character-relevant issues, such as how to consider others' perspectives and feelings, how to respond to teasing and bullying, and how to ask for, give, and receive forgiveness.

\section{Method}

\section{Participants}

The AIM unit under investigation in the present study was piloted at a public school in the northeastern United States that educates children from kindergarten through eighth grade. The school serves a population of students from culturally diverse backgrounds with $45.1 \%$ of students' identifying as Hispanic; $26.6 \%$ as White; $14.2 \%$ as African American; $13.2 \%$ as Asian; and $1.0 \%$ as multi-race, non-Hispanic. The school also incorporates Sheltered English Immersion and Special Education programs. About $83 \%$ of students are eligible for free or reduced lunch.

For the current study, we implemented the program unit with all students in the first $(n=32)$, second $(n=21)$, fourth $(n=46)$, and fifth $(n=46)$ grade classrooms. Within this sample, we recorded and transcribed data from the IGN experience from a subset of 27 cross-age peer dyads in which both students provided consent. The 27 dyads included 13 first-fourth grader dyads and 14 second-fifth grader dyads. Eleven of the dyads were male-male dyads, 11 were female-female dyads, and five were cross-sex dyads in which the older peer was male. We also surveyed eight of the ten teachers whose classrooms participated in the study. 


\section{Procedure}

This study received approval from a university Institutional Review Board at as well as the relevant school staff. Teachers or school personnel obtained parental consent for participation through an information packet sent home with each child. Packets contained a letter explaining the AIM program and consent and assent forms. All students within each classroom participated in the AIM unit; however data were only collected from students who received parental consent and assented to participation.

The implementation of the program involved several steps. First, we conducted a one hour teacher training with the participating teachers. During the training, teachers were provided with a teachers' manual and an overview of the project. The teachers were able to see and experience how to the IGN worked, and they were introduced to the lessons plans for the four sessions that made up the AIM program unit. Next, we worked with teachers to pair Little Buddies in first and second grade with Big Buddies in fourth and fifth grade, so that the most appropriate Buddy pair matches were made based on maturity of the students, sociability, and communication difficulties. In addition, consented Little Buddy participants were paired with other consented Big Buddy participants to facilitate data collection. Finally, the pilot program was broken into four classroom sessions, each lasting 30 to 40 minutes. Each session was conducted with the assistance of researchers and is described in more detail below ${ }^{1}$.

Session one: Getting ready to meet your Buddy. In session one, teachers prepared Big Buddies for the experience by introducing them to the purpose of the project, discussing and practicing how to be a good Big Buddy, and how to engage with the IGN and its storyline. Little Buddies were also prepared by their teachers about the project and how to talk to their Big Buddies. During session one, Little Buddies and Big Buddies also drew self-portraits in their respective classrooms and included basic information about themselves, including their favorite food, favorite color, and dreams.

Session two: Getting to know your Buddy. Session two served as a "Meet and Greet," an opportunity for students to meet their respective buddy and become more familiar with one another. Students convened in a single classroom to exchange self-portraits and meet their buddy. This time was intended for buddies to get acquainted before interacting with the IGN.

Session three: Reading and talking together. During session three, Buddy pairs were seated at a desktop or laptop computer to engage with the IGN. Each computer was prepared prior to the arrival of the peer dyads to decrease the potential for technical difficulties. The IGN homepage, sourced on the official PBS hosted Arthur website, ${ }^{2}$ was displayed at the time of buddies' arrival and the audio was set to an appropriate volume. Buddy pairs were instructed to view the story presented in the IGN, answer prompted questions that appeared at various points throughout the story, and make decisions about the three different endings to the story (see Figures 2 and 3). Engagement with the IGN lasted approximately 35 minutes. Following the completion of the IGN, teachers facilitated a brief group discussion with all of the peer dyads about the story.

\footnotetext{
${ }^{1}$ The full set of training materials, including the teachers' guide, is available upon request from the Institute for Applied Research in Youth Development (IARYD).

${ }^{2}$ The IGN homepage can be found at: http://pbskids.org/arthur/games/comic sofunny/index.html
} 
Figure 2

Screenshots of the interactive screens embedded in the Arthur interactive graphic novel (IGN).
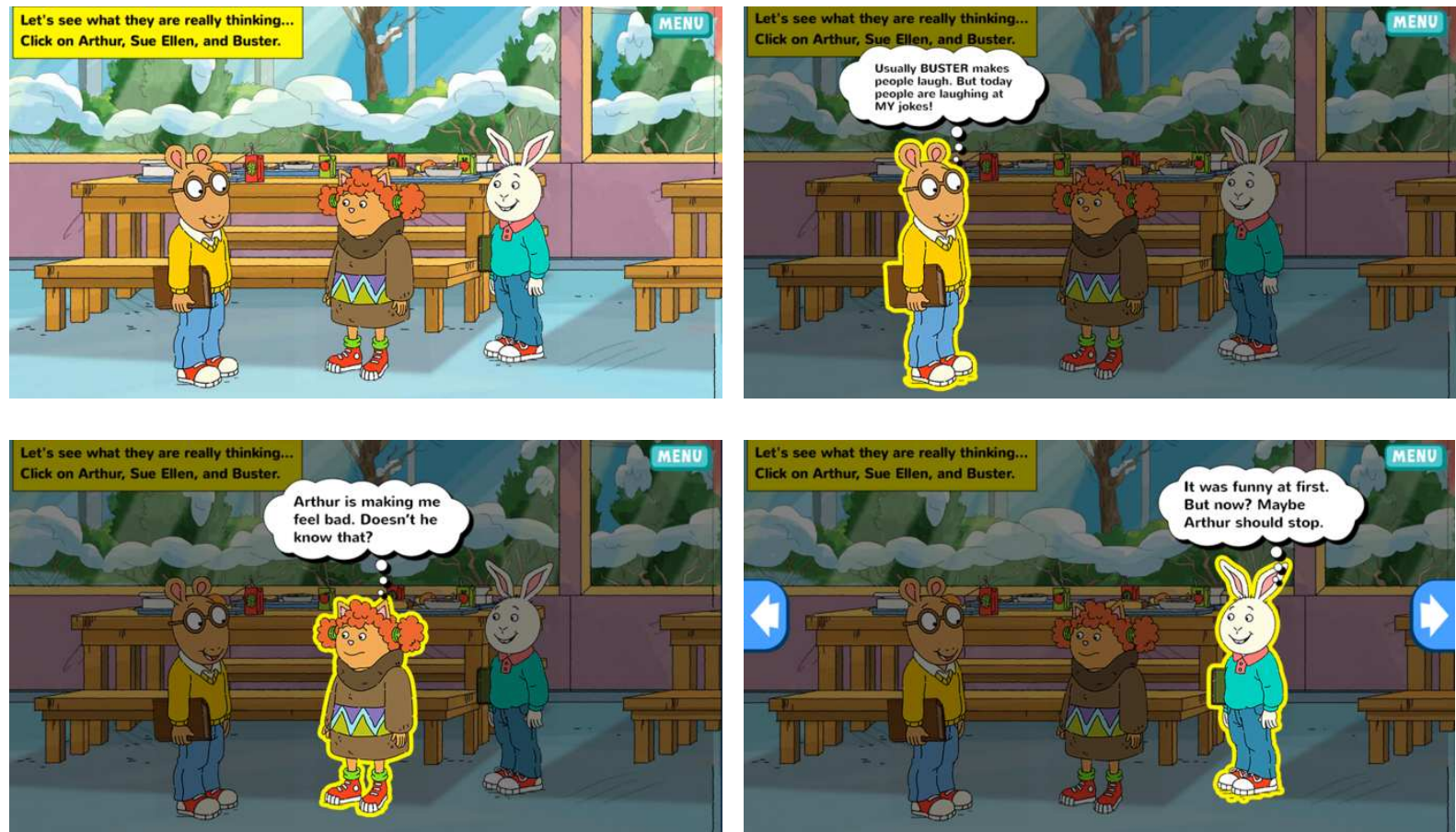

(C) 2015 WGBH Educational Foundation. All rights reserved. "Arthur" \& the other Marc Brown ARTHUR characters and underlying materials (including artwork) TM and (C) Marc Brown. The Arthur Interactive Media Buddy Project was made possible through the support of a grant from the John Templeton Foundation. The opinions expressed in this publication are those of the author(s) and do not necessarily reflect the views of the John Templeton Foundation.

\section{Figure 3}

Screenshots of the story ending options from the Arthur interactive graphic novel (IGN).

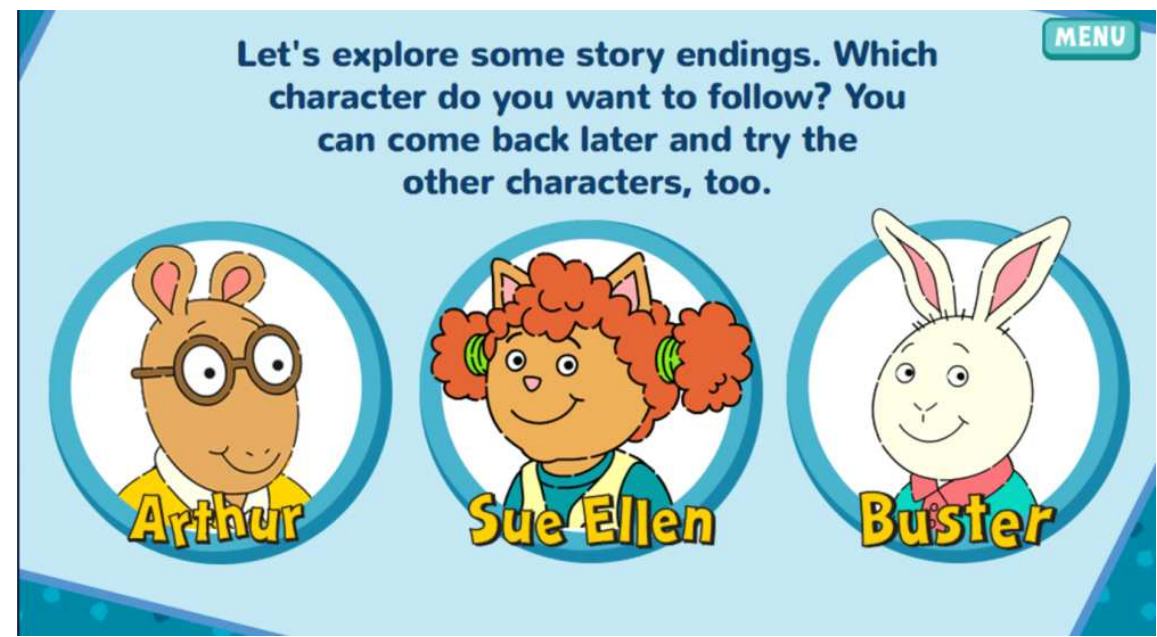




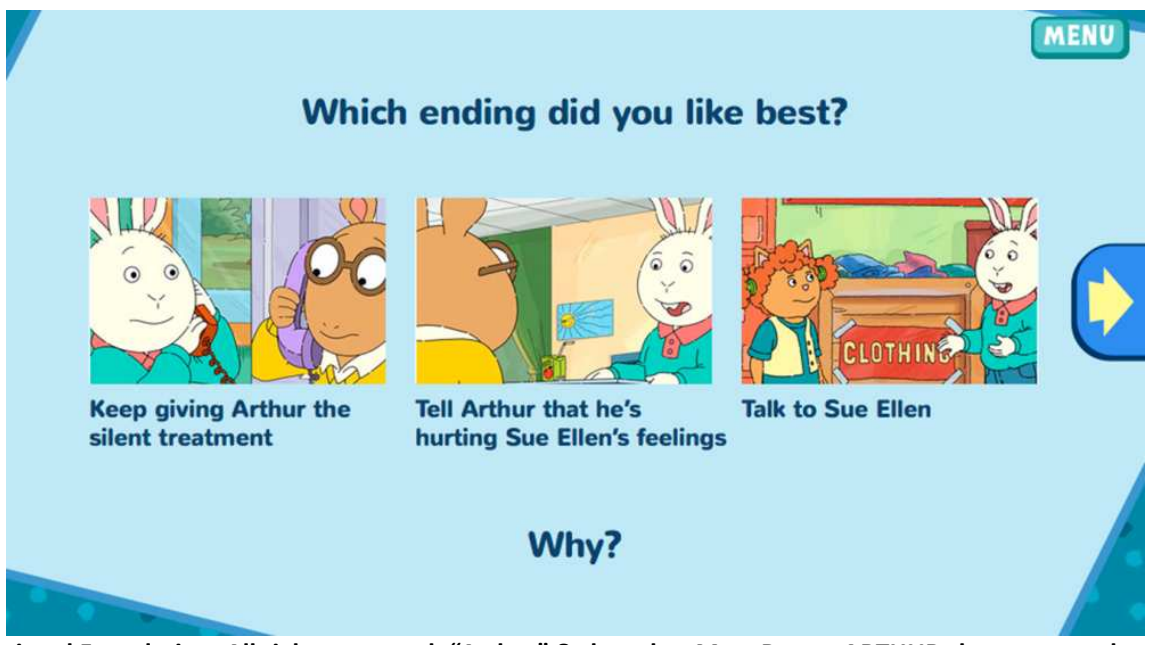

(c) 2015 WGBH Educational Foundation. All rights reserved. "Arthur" \& the other Marc Brown ARTHUR characters and underlying materials (including artwork) TM and (C) Marc Brown. The Arthur Interactive Media Buddy Project was made possible through the support of a grant from the John Templeton Foundation. The opinions expressed in this publication are those of the author(s) and do not necessarily reflect the views of the John Templeton Foundation.

Session four: Reflecting together. In Session four, Buddy pairs reconvened in a single classroom to review the story presented in the IGN during the previous session to create a list of "Good Buddy Guidelines." Again, teachers facilitated this discussion allowing time for peer dyads to discuss the story in pairs and then share their thoughts with the class. Following the discussion, "Buddy" pairs collaborated to create a poster of their favorite "Good Buddy Guidelines," such as "treat others nicely," "make sure to ask your friends how they are feeling," and "be sure to apologize when you hurt someone."

\section{Data collection and analysis}

Usability. To gauge the usability of the IGN, satisfaction with the materials, and student engagement, we provided teachers with a brief questionnaire. The questionnaire asked teachers to respond to three items about each session of the program. First, teachers were asked to rate their overall satisfaction with the content provided for a particular session on a scale from $0=$ Disappointed to $4=$ Very Satisfied. Next, teachers were asked to rate their perceived level of student engagement during each session on a scale for $0=$ Not engaged at all to $3=$ Very engaged. Third, teachers were asked to provide open-ended responses about the changes they think would be helpful for each session. Finally, we also asked teachers to provide their overall attitudes about the AIM program to help plan future materials.

Amount of dyad conversation. To gather data on the students' level of engagement with the IGN in terms of how much and what type of talk was produced, we recorded and transcribed the conversations between 27 Buddy pairs as they went through the IGN storyline. Peer dyad interactions with the IGN were video recorded using handheld recording devices placed in front of each peer dyad prior to the arrival of students. The peer dyad conversations from these recordings were then professionally transcribed. Throughout all data collection a detailed protocol was used to standardize the collection process. The protocol contained information relevant to the operation of the IGN, volume, and screen settings of each computer or laptop used, as well as video recorder functions (Druin, 1999). Prior to analysis, each transcript underwent a series of edits conducted by the research team. First, the accuracy of the transcripts was checked by comparing transcript content to corresponding video recordings. Second, transcripts were checked with videos files to confirm Big Buddy and Little Buddy identities. 
To code for the amount of conversation, we analyzed Buddy conversations that occurred in response to each of the questions that were embedded within the IGN (e.g., "Was Sue Ellen upset? How do you know?"). We coded responses on a scale of 0 to 3 . Responses that were coded $O$ reflected no conversation resulting from any given question. Responses that were coded 1 reflected conversation in which the one Buddy provided a response or comment, but the other Buddy did not respond beyond saying "yes" or "no." Responses that were coded 2 reflected conversation in which Buddy pairs engaged in back and forth interactions. Finally, responses that were coded 3 reflected conversations in which Buddy pairs had more detailed or nuanced back and forth discussions, in which story themes were discussed, personal experiences were shared, or hypothetical situations were posed.

Content of dyad conversations. For the larger AIM study, we have identified several character virtues that have been linked to prosocial behavior and positive development in children (e.g., Damon, 1988; Eisenburg, Spinrad, \& Knafo, 2015). These character virtues humility, intellectual humility, forgiveness, generosity, honesty, love, creativity, and futuremindedness - are especially essential for children to successfully interact with their peers as well as adults, and to build meaningful social bonds (e.g., Davis et al., 2013).

To code for specific character virtues implicitly or explicitly being discussed during buddies' conversations, we used an iterative and deductive-inductive process to arrive at the code categories for analyzing the Buddy transcripts. We developed an initial coding manual based on the theoretical definitions and empirically validated measures of each character virtue. The research team revised this coding manual through an iterative process of comparing children's language in three randomly selected sample dyads from the set of 27 to the character virtue codes until a clear set of codes was consensually reached by the team.

Throughout the open-coding process, we engaged in multiple forms of note taking to identify and explore terms, concepts, and processes consistent with the definition of the character virtues and that were reflected in the Buddies' responses. The goal of this coding system was to assess the substance of Buddies' conversations in response to questions and situations presented via the IGN story and to assign codes based on the information and ideas participants expressed in their comments. This approach differs from global approaches to freeresponse coding since only the content of participants' spoken statements is assessed. Therefore, the current approach focuses primarily on what information and ideas the participants communicate. The main assumption in this methodological approach is that participants' spoken responses reflect their beliefs, conceptualizations, or thinking about what is occurring in the story. Thus, the present system is designed to assess how children think about Arthur and his friends, the situations presented, and their own experiences with similar situations. The entire process of coding manual revisions and recoding of transcripts continued until acceptable interrater reliability (i.e., Cohen's kappa $>.70$ ) was achieved ${ }^{3}$. All transcripts were double-coded by members of the research team.

We present below the operational definitions and descriptions of the three primary character virtues investigated in this study. The virtues under investigation were humility, forgiveness, and future-mindedness, due to their relevance to the storyline as well as the number of times that aspects or attributes related to these virtues came up (compared to other attributes related to other virtues, such as love or honesty).

\footnotetext{
${ }^{3}$ The final full coding manual is available upon request from the Institute for Applied Research in Youth Development.
} 
Humility, Given the content of the IGN, aspects related to the character virtue of humility were most prominent in Buddies' conversations. Because there is no psychometrically strong measure of humility for young children, we relied on the limited extant literature describing key concepts of humility that children are capable of understanding (see Davis et al., 2010, 2011, 2013; Echols \& Finkbiner, 2013). According to Echols and Finkbiner (2013), for instance, humility reflects both a modest view of oneself as well as openness to new ideas and the practices of others. Thus, a humble person would avoid overt praise and recognition and rather, would recognize and respect the contributions of others. Davis, Worthington, and Hook (2010) also define humility as a relationship-specific virtue comprised of other-orientedness (e.g., perspective taking), positive other-oriented emotions (e.g., compassion), self-regulation, and an accurate sense of self. In the current IGN, Arthur shows lack of humility in that he refuses to acknowledge why his actions and words hurt Sue Ellen's feelings, and he writes an insincere apology letter that only makes matters worse.

Based on the coding process integrating the conceptualization and proposed definition of humility with the available data in the storyline and Buddies' conversations, we arrived at a total of ten code categories to represent humility or talk surrounding the concept of humility: affect labeling, perspective taking, empathic responding, sympathy, "owning" ones' mistakes, openness, learning from others, modest self-worth, envy/jealousy, and pride.

Forgiveness. Forgiveness refers to one's willingness to release resentment and retaliation toward those who may have caused one harm (Hargrave, 1994), restoring relationship trust, and healing inner emotional wounds (DiBlasio \& Proctor, 1993). As indicated in the humility section, Arthur writes an insincere apology letter in the IGN, and the Buddies reflect on what that means for all characters involved. Based on the coding process integrating the definition of forgiveness with the available data in the storyline and Buddies' conversations, we arrived at a total of five code categories: saying sorry, importance of apologizing, consequence for apologizer, consequences for receiver; and difficulty of forgiveness.

Future-mindedness, Future-mindedness has components that are cognitive (e.g., the extent to which one thinks about the future), attitudinal (e.g., the extent to which one prefers longterm to short-term goals), and motivational (e.g., the extent to which one formulates plans to achieve long-term goals). The mostly widely used model of future orientation (Steinberg et al., 2009) has three components: time perspective, anticipation of future consequences, and planning ahead. During engagement with the IGN, future mindedness was clearly illustrated as Buddies discussed the decisions Arthur or his friends must make, and the possible implications of those decisions. Based on the coding process integrating the definition of future-mindedness with the available data in the storyline and Buddies' conversations, we arrived at a total of five code categories: consequences, planning for action, long-term picture; hope, and predicting.

\section{Results}

The results are presented in three sections based on the source of data available. First, we present teachers responses to the survey items, integrating the quantitative responses to the Likert items with representative qualitative responses from the open-ended items. We then present quantitative findings on how much conversation occurred within the dyads in response to the questions embedded in the IGN, followed by a description of the content of the conversations (i.e., whether those conversations were marked by character-relevant talk). . 
Teacher-reported satisfaction and student engagement

In regard to satisfaction, teachers responded very favorably to the IGN and related materials. On average, teachers rated high satisfaction with the overall set of materials $(M=3.53 ; \mathrm{S} D=$ .60); that is, $94 \%$ of teachers reported that they were "very satisfied" with the overall program experience. For example, one second grade teacher reported that she was "very impressed with the materials, organization and professionalism of the program" and that "bullying is such an important topic- the more kids have the opportunity to discuss it, the better they'll be able to handle it."

In regard to student engagement, teachers on average reported that children were "very engaged" with the sessions $(M=2.74, S D=.50)$; that is, teachers reported that students were fully engaged $88 \%$ of the time across the entire program experience. Looking at just Session 3 , $100 \%$ of teachers reported that the students were very engaged with the IGN. For example, a fifth grade teacher noted that she was "so impressed with the engagement of all 'Buddies' 'Big' and 'Small,' and she "did not expect the level of discussion that occurred."

In addition, teachers also reported incorporating the experience into the broader curriculum and identifying benefits to multiple student populations. A first grade teacher reported that the AIM unit "was accessible to my English language learning students and students with special needs." Similarly, a second grade teacher pointed out that, "The vocabulary was amazing! Some of my students are still saying 'très chic!' The pictures really helped them learn the words."

\section{Amount of peer dyad conversation}

In examining the peer dyad conversations, we first analyzed the type of dyad discussions that resulted in response to the questions embedded within the IGN (e.g., "How does Sue Ellen feel about the jokes? How do you know?"). Examining the discussions that occurred after the embedded questions in the IGN, we found that the IGN promoted substantive conversation. During these discussions, dyads engaged in brief back and forth discussions $48.6 \%$ of the time and more engaged discussions $41.9 \%$ of the time. In $7.7 \%$ of the responses, youth engaged in deep discussions that were connected to their own experiences or indicated a more nuanced understanding of the IGN content and material. For example, one Little Buddy related Arthur and his friends' experience to their own experiences of bullying: "This other kid came over and said, 'Get away from her, she's little! Leave her alone!' So I was really, really happy."

\section{Content of peer dyad conversation}

Examining the responses to the embedded questions, we found that Buddies not only engaged in conversations, but that $94 \%$ of their conversations were directly relevant to character. The most frequent character virtues that were coded included humility $(78.4 \%)$, future-mindedness $(33.5 \%)$, and forgiveness $(7.5 \%)$. The large number of responses involving humility were expected given that the storyline presented children with ample opportunities to discuss aspects of humility, including Arthur's selfish perspective or lack of self-awareness that he's hurting Sue Ellen. Overall, the most frequently coded virtue subcategories included affect labeling and perspective taking (humility), the importance of apologizing (forgiveness), and reflections on the consequences of characters' actions (future-mindedness). Below is an excerpt from another Buddy conversation in which the Buddies discuss the feelings and perspectives of Arthur and his friends:

Big Buddy (Boy): Look at her (Sue Ellen), she looks, she looks, um, looks unhappy over here cause she's frowning, and he's (Arthur) just happy over here. And he thinks that... 
Little Buddy (Girl): Yeah, cause he's (Arthur) makin' the jokes. He's making the jokes up of her and she's (Sue Ellen) just playing that, she's just pretending that she's happy. And then she's just playing, playing along, but she's actually really sad.

Big Buddy (Boy): Yeah, I think that she's (Sue Ellen) really upset.

Beyond the character virtues, students also identified and labeled a 'bad behavior' frequently, as well as encouraged Arthur's friends to report the 'bad behavior' to an adult. These instances were coded in $10 \%$ of the opportunities. The Buddies explored many important topics through these conversations. For example, many Little Buddies conceptualized bullying as physical only, but Big Buddies helped them expand their definition of bullying to include verbal bullying as well. Here is part of a transcript from two boys, a first and $4^{\text {th }}$ grader, highlighting this type of conversation.

Little Buddy (Boy): I think maybe Arthur because Arthur is a bully, but that's not bullying. . Bullying, that means you hit someone.

Big Buddy (Boy): No, bullying is not just hitting. It's making fun. It's just bad things hitting, it's not just hitting. It's hitting and hurting... Well, bullying is still if you make fun of someone, if you hurt someone. That's bullying.

In addition, many Little Buddies had a hard time discerning between playful talk among friends and hurtful teasing, but as the IGN progressed, they were able to better differentiate between the two with the help of their Big Buddy.

Big Buddy (Girl): Was it a good joke or a bad joke?

Little Buddy (Girl): Bad joke.

Big Buddy (Girl): Why?

Little Buddy (Girl): Because that's - because I would not like people calling me names like that.

Big Buddy (Girl): She got angry. He's still laughing. What would you tell him to do? Little Buddy (Girl): I would tell him to stop and go tell a teacher.

\section{Discussion}

Over the past two decades, schools have tried to integrate both character education and technology into a full class schedule (Gray, Thomas, \& Lewis, 2010). Over the same period, OST programs have also been tasked with promoting the "whole child," so as to exhibit high character and the necessary skills for success in the $21^{\text {st }}$ century (National Research Council, 2012). In the context of these changes, we investigated whether a unit from the initial development of the Arthur Interactive Media (AIM) program showed effective usability as well as meaningful character-relevant conversations between cross-age peers. We were interested in whether teachers liked the program, whether the program was engaging to children, and whether the interactive graphic novel (IGN) experience was associated with conversations relevant to character in the cross-age peer dyads. As an initial study on the link between digital media and character among young children, we are aware of the limitations of the present research. For example, these limitations pertain to sampling, and therefore generalizability to other groups; sample size, and thus power; the use of a cross-sectional design, and therefore the absence on intraindividual change data; and the absence of cross-validation data derived from other IGNs. Nevertheless, the findings of the present research are useful in several ways.

We found that the preponderant majority of participating teachers reported they were "very satisfied" with the AIM program and that students were fully engaged with the program materials, and all teachers reported students were "very engaged" during the IGN session in 
particular. During their joint engagement with the IGN, children conversed with their cross-age peers, and these conversations were marked by character-relevant talk. Based on 1. theory and research linking peer dialogue to moral development (Damon, 1988; Larson et al., 2012; Walker et al., 2000); 2. the use of technologies to engage and encourage reflection and knowledge construction (Jonassen et al, 2003); and 3. research indicating positive associations between positive media content and prosocial behavior (Narvaez et al., 2008), we believe that the AIM program promotes character-relevant conversations between cross-age peers and also carries the potential to promote character development in children.

Consistent with the "Big 3" (Lerner, 2004) and "SAFE" principals (Durlak et al., 2010) of effective programs that can be applied to OST settings, we also believe that the AIM program has great potential to impact character education in a variety of settings, such as after-school and at-home (i.e., family engagement). Although the current study findings are derived from the program as implemented in a school-setting, there exists major potential and implications for the program to be applied to OST settings. The ease of IGN implementation seems to complement the teacher's enthusiasm for and child engagement with the materials, making a strong case for the AIM program as a relatively easy to implement, high-yield prevention intervention for use in varied youth settings.

In addition, forms of digital media are a ubiquitous part of most children's lives at earlier and earlier ages (Bers \& Kazakoff, 2013). Yet, most research has focused on the negative implications of media use (e.g., Ferguson, 2013). Many recommendations about media use are predicated on the idea that children should have little exposure to various forms of media but, as well, point to possible prosocial benefits of media when used innovatively (American Academy of Pediatrics, 2013). Prosocial content provided through digital media may promote emotional competencies and reduce aggressive thoughts (Narvaez et al., 2008). Therefore, it is important to understand how children are using technology and media and whether these practices are appropriately supporting children's development.

The results from the current evaluation of one unit of the initial development of the AIM program provide some, albeit preliminary, support for the idea that the innovative use of technology may promote character-relevant conversations and reflections, or processes linked to stronger character (Nucci, 1997). We found that during the IGN session, children were not only engaged with the digital media, but, as well, in conversations with each other. During these conversations, cross-age peer dyads engaged in at least brief back and forth discussions about a dimension of character about half of the time, or in more engaged discussions about character-relevant issues also about half of the time. Peer dyads not only engaged in conversations, but they engaged in conversations about character in a vast majority of the possible opportunities. Therefore, the present study extends research on potential learning from joint media engagement (Takeuchi \& Stevens, 2011) to a new domain (character) and a new relationship (cross-age peers).

Given the purpose of the specific IGN evaluated in the current study, it is not surprising that the most frequent character virtues that were identified in children's conversations were humility, future-mindedness, and forgiveness. These character virtues have been linked to prosocial behavior in children (e.g., Damon, 1988; Eisenberg et al., 2015), and are essential for successfully interacting with others (e.g., Davis et al., 2013). However, it is important to note that our operationalization of humility was somewhat limited in scope due to the difficulty of defining and assessing humility in children of this age. Although both perspective taking and empathy overlap with components of humility as defined by Davis and colleagues (2010), we 
were not able to capture the character virtue humility fully. Future research is needed to examine whether the established code categories are valid indicators of humility.

Beyond character virtues, children also labeled a bad behavior frequently or encouraged Arthur's friends to report his behavior to an adult only a small proportion of the time. In addition, the dyads explored how to clearly identify bullying behaviors and how to differentiate between bullying, teasing, and playful talk. These findings are consistent with prior work examining children's definitions of bullying and reflect developmental differences (Smith et al, 2002). That is, Smith and colleagues (2002) found that, whereas eight-year-olds were able to discriminate just nonaggressive from aggressive cartoon situations, 14-year-olds had much more nuanced understandings of these behaviors and were able to discriminate fighting from physical bullying, verbal bullying, and social exclusion.

Of course, whereas children were able to identify the character-relevant issues present in the IGN, these cognitive skills may not translate to other situations in which the characteristics and demands of those situations are different (e.g., when the child is the victim or perpetrator of teasing in real life) or whether the content of the discussions is retained for future use. For example, an important future direction for this work would be to include a post-test to assess whether children understand and can successfully identify novel instances of verbal bullying. Moreover, we do not know if children's words will be reflected in their actions. Therefore, future work with the AIM program should examine the link between the amount and type of characterrelevant talk by children and their actual behaviors, both in school and out of school, so as to determine whether use of the IGN creates long-term, generalizable retention of the characterrelevant issues.

\section{Conclusions}

Promoting character in children is a complex but worthwhile effort. To the extent that practitioners seek authentic and effective programming to promote "good" character, and ultimately, prosocial behavior, in young people, it is important to understand the various processes that contribute to character. We have described initial research about a program that provided some support for the idea that peers and interactive technology can work in concert in promoting character-relevant conversations among children. This study also provided support for the usefulness of the materials we used. We believe that, as part of a more comprehensive curriculum, a child's regular active engagement with Arthur-based materials, in collaboration with the guidance of an older peer, will influence youth character and, ultimately, youth prosocial behaviors, peer relations, and overall school climate.

\section{References}

American Academy of Pediatrics Council on Communications and Media (2013). Children, adolescents, and the media. Pediatrics, 132, 958-961.

Bailey, B., Tettegah, S., \& Bradley, T. (2006). Clover: Connecting technology and character education using personally-constructed animated vignettes. Interact. Comput. 18(4), 793-819.

Barber, B.K., \& Olsen, J.A. (1997). Socialization in context connection, regulation, and autonomy in the family, school, and neighborhood, and with peers. Journal of Adolescent Research, 12(2), 287-315. 
Bers, M., \& Kazakoff, E. (2013). Techno-Tykes: Digital technologies in early education. In O. Saracho \& B. Spodek (Eds.), Handbook of research and the education of young children (3rd ed., pp. 197-205), London: Routledge.

Burrell, B., Wood, S., Pikes, T., \& Holliday, C. (2001). Student mentors and proteges: Learning together. The Council for Exceptional Children, 33, 24-29.

Calvert, S.L. (2015). Children and digital media. In M.H. Bornstein and T. Leventhal Eds.), Handbook of Child Psychology and Developmental Science (7th ed., pp. 375-415), Volume 4: Ecological Settings and Processes in Developmental Systems. Editor-in-chief: R.M. Lerner. Hoboken, N.J.: Wiley.

Cassidy, K.W., Werner, R.S., Rourke, M., Zubernis, L.S. \& Balaraman, G. (2003). The relationship between psychological understanding and positive social behaviors. Social Development, 12, 198-221.

Clark, K. (1998). Intersection of instructional television and computer assisted learning: Implications for research paradigms. In J. Asamen \& G. Berry (Eds.), Research paradigms in the study of television and social behavior (pp. 287-304). Newbury Park, CA: Sage

Damon, W. (1988). The moral child: Nurturing children's natural moral growth. New York, NY: Free Press.

Damon, W. (2008). The path to purpose: How young people find their calling in life. New York, NY: Simon \& Schuster:

Davis, D.E., Hook, J.N., Worthington Jr., E.L., Van Tongeren, D.R., Gartner, A.L., Jennings, D.J., \& Emmons, R.A. (2011). Relational humility: Conceptualizing and measuring humility as a personality judgment. Journal of Personality Assessment, 93, 225-234.

Davis, D.E., Worthington Jr., E.L., \& Hook, J.N. (2010). Humility: Review of measurement strategies and conceptualization as personality judgment. The Journal of Positive Psychology, 5(4), 243-252.

Davis, D., Worthington Jr., E.L., Hook, J.N., Emmons, R.A., Hill, P.C., Bollinger, R.A., \& Van Tongeren, D.R. (2013). Humility and the development and repair of social bonds: Two longitudinal studies. Self and Identity, 12, 58-77.

DiBlasio, F.A., \& Proctor, J.H. (1993). Therapists and the clinical use of forgiveness. American Journal of Family Therapy, 21(2), 175-184.

Druin, A. (1999). Cooperative inquiry: Developing new technologies for children with children. Human Factors in Computing Systems: CHI 99 (pp. 223-230). New York: ACM.

Durlak, J.A., Weissberg, R.P., \& Pachan, M. (2010). A meta-analysis of after-school programs that seek to promote personal and social skills in children and adolescents. American Journal of Community Psychology, 45(3-4), 294-309.

Echols, M., \& Finkbiner, L. (2013). The development of children's understanding of humility. Chrestomathy: Annual Review of Undergraduate Research, 12, 1-23. 
Eisenberg, N., Spinrad, T.L., \& Knafo-Noam, A. (2015). Prosocial Development. In M.E. Lamb (Vol. Ed.) and R.M. Lerner (Series Ed.), Handbook of child psychology: Vol. 3. Social, emotional, and personality development (7th ed, pp. 610-656). New York: Wiley.

Farrington, D., \& Ttofi, M. (2009). School-based programs to reduce bullying and victimization. Washington, DC: Campbell Corporation.

Ferguson, C.J. (2013). Violent video games and the Supreme Court: Lessons for the scientific community in the wake of Brown v. Entertainment Merchants Association. American Psychologist, 68, 57-74.

Gray, L., Thomas, N., \& Lewis, L. (2010). Teachers use of educational technology in U.S. public schools: 2009. National Center for Education Statistics, Institute of Education Sciences, U.S. Department of Education. Washington, D.C.

Hargrave, T.D. (1994). Families and forgiveness: A theoretical and therapeutic framework. The Family Journal, 2(4), 339-348.

Jonassen, D., Howland, J., Moore, J., \& Marra, R. (2003). Learning to solve problems with technology: A constructivist perspective. Upper Saddle River, NJ: Merrill Prentice Hall.

Karcher, M.J. (2007). Cross-age peer mentoring. Youth Mentoring: Research in Action, 1(7), 317.

Kohlberg, L. (1969). Stage and sequence: The cognitive-developmental approach to socialization (pp. 347-480). New York: Rand McNally.

Lapsley, D.K., \& Narvaez, D. (2006). Character education. In A. Renninger \& I. Siegel (Eds.) and W. Damon \& R. Lerner (Editors-in-Chief.), Handbook of child psychology: Vol. 4. Child psychology in practice (6 ${ }^{\text {th }}$ ed., pp. 248-296). New York: Wiley.

Larson, R.W., Jensen, L.A., Kang, H., Griffith, A, \& Rompala, V. (2012). Peer groups as a crucible of positive value development in a global world. In Trommsdorff, G., \& Chen, X. (Eds.), Values, Religion, and Culture in Adolescent Development (pp. 164- 187). Cambridge: Cambridge University Press.

Lerner, R.M. (2004). Liberty: Thriving and civic engagement among America's youth. Sage Publications.

Lerner, R.M., \& Callina, K.S. (2014). The study of character development: Towards tests of a relational developmental systems model. Human Development, 57, 322-346.

Lerner, R.M., Lerner, J.V., Lewin-Bizan, S., Bowers, E.P., Boyd, M., Mueller, M., Schmid, K., \& Napolitano, C. (2011). Positive youth development: Processes, programs, and problematics. Journal of Youth Development, 6(3), 40 - 64.

Myers, D. (2000). The American paradox: Spiritual hunger in an age of plenty. New Haven, CT: Yale University Press.

Narvaez, D., Mattan, B., MacMichael, C., \& Squillace, M. (2008). Kill bandits, collect gold or save the dying: The effects of playing a prosocial video game. Media Psychology Review,1(1).

Retrieved from http://mprcenter.org/mpr/index.php?option=com_content \&view= article\&id=35\& Itemid $=121$ 
National Research Council. (2012). Education for life and work: Developing transferable knowledge and skills in the 21st century. Committee on Defining Deeper Learning and 21st Century Skills, J.W. Pellegrino \& M.L. Hilton, Editors. Board on Testing and Assessment and Board on Science Education, Division of Behavioral and Social Sciences and Education. Washington, DC: The National Academies Press.

Nucci, L.P. (1997). Moral development and character formation. In H.J. Walberg, \& G.D. Haertel (Eds.), Psychology and Educational Practice (pp. 127-157). Berkeley, CA: MacCarchan.

Peterson, C., \& Seligman, M.E.P. (2004). Character strengths and virtues: A handbook and classification. Washington, DC: American Psychological Association.

Sestir, M., \& Bartholow, B. (2010). Violent and nonviolent video games produce opposing effects on aggressive and prosocial outcomes. Journal of Experimental Social Psychology, 46(6), 934-942.

Smith, P.K., Cowie, H., Olafsson, R.F., Liefooghe, A.P., et al. (2002). Definitions of bullying: A comparison of terms used, and age and gender differences, in a Fourteen-Country international comparison. Child Development, 73(4), 1119-1133.

Sojourner, R.J. (2012). The rebirth and retooling of character education in America. Retrieved from http://www.character.org/wp-content/uploads/Character-Education.pdf

Steinberg, L., Graham, S., O’Brien, L., Woolard, J., Cauffman, E., \& Banich, M. (2009). Age differences in future orientation and delay discounting. Child Development, 80, $28-44$.

Stevens, R., Satwicz, T., \& McCarthy, L. (2008). In-game, in-room, in-world: Reconnecting video game play to the rest of kids' lives. The ecology of games: Connecting youth, games, and learning, 9, 41-66.

Takeuchi, L., \& Stevens, R. (2011). The new coviewing: Designing for learning through joint media engagement. In New York, NY: The Joan Ganz Cooney Center at Sesame Workshop.

Tasca, A. (2002). Teaching and Learning in Science Through a Science Buddies Programs. Investigating: Australian Primary \& Junior Science Journal, 18, 16-19.

Tettegah, S. (2005). Technology, narratives, vignettes, and the intercultural and cross-cultural teaching portal. Urban Education, 40 (4), 368-393.

Turner, V.D., \& Berkowitz, M.W. (2005). Scaffolding morality: Positioning a socio-cultural construct. New Ideas in Psychology, 23(3), 174-184.

Walker, L., Hennig, K., \& Krettenauer, T. (2000). Parent and peer contexts for children's moral reasoning development. Child Development, 71(4), 1033-1048.

(C) Copyright of Journal of Youth Development Bridging Research and Practice. Content may not be copied or emailed to multiple sites or posted to a listserv without copyright holder's express written permission. Contact Editor at: patricia.dawson@oregonstate.edu for details. However, users may print, download or email articles for individual use.

ISSN 2325-4009 (Print); ISSN 2325-4017 (Online) 